\title{
PRODUÇÃO E OTIMIZAÇÃO DO BIODIESEL DE ÓLEO DE BACABA (OENOCARPUS BACABA MART.)
}

Joel dos Santos Batista ${ }^{a}$, Valdomiro Lacerda Martins ${ }^{\text {b }}$.

a Instituto de Ciências Exatas e Tecnologia (ICET), Universidade Federal do Amazonas (UFAM) . Rua Nossa Senhora do Rosário, 3863, Tiradentes, Itacoatiara-AM, Brasil. CEP. 69103-128.

b Instituto de Ciências Exatas e Tecnologia (ICET), Universidade Federal do Amazonas (UFAM) . Rua Nossa Senhora do Rosário, 3863, Tiradentes, Itacoatiara-AM, Brasil. CEP. 69103-128.

\section{RESUMO}

Na Amazônia o gênero Oenocarpus bacaba MART é usado para extração da polpa e as sementes são jogadas quando poderia retirar o óleo para produção de biodiesel. O trabalho focou-se na produção e estudo das variáveis que afetam no rendimento como temperatura, catalisador, metanol e tempo. O rendimento para extração ficou em $15.51 \%$ de $1000 \mathrm{~g}$ da matéria prima, valor próximo do algodão e soja $15 \%$ e $18 \%$, o índice de acidez foi de 1,92 mg $\mathrm{KOH} / \mathrm{g}$ para o óleo bruto, e $179 \mathrm{mg} \mathrm{KOH} / \mathrm{g}$ para a saponificação, dentro de valores encontrados na literatura. $\mathrm{O}$ rendimento foi melhor em temperatura ambiente que a temperatura elevada uma vez que ficou entre $78 \%$ e $86 \%$ de biodiesel, porém o índice de acidez para os 16 ensaios mostrou que o biodiesel tem pouca estabilidade a oxidação, em vista que o valor limite é de $0,50 \mathrm{mg} \mathrm{KOH} / \mathrm{g}$ e para o trabalho os valores foram de 0,52 a 0,71. Conclui-se que a bacaba tem potencial para extração do óleo visto que a matéria prima seria descartada no lixo, porém a estabilidade deve ser estudada.

Palavras-chave: Biodiesel, Bacaba, Planejamento fatorial

\section{ABSTRACT}

In the amazon the genus Oenocarpus bacaba MART is used for pulp extraction and the seeds are thrown when it could remove the oil for biodiesel production. The work focused on the production and study of variables that affect yield such as temperature, catalyst, methanol, and time. The yield for extraction was $15.51 \%$ of $1000 \mathrm{~g}$ of raw material, a value close to cotton and soy $15 \%$ and $18 \%$, the acidity index was $1.92 \mathrm{mg} \mathrm{KOH} / \mathrm{g}$ for crude oil, and 179 $\mathrm{mg} \mathrm{KOH} / \mathrm{g}$ for saponification, within values found in the literature. The yield was better at room temperature than the high temperature since it was between $78 \%$ and $86 \%$ biodiesel, but the acidity index for the 16 tests showed that biodiesel has little stability to oxidation, since the limit value is $0.50 \mathrm{mg} \mathrm{KOH} / \mathrm{g}$ and for the work the values were 0.52 to 0.71 . It is concluded that bacaba has potential for oil extraction since the raw material would be discarded in the garbage, but the stability should be studied.

Keywords: Biodiesel, Bacaba, Factorial Planning

*Autor correspondente: Joel dos Santos Batista a, Graduação em Química Industrial , Beco 14 de Agosto, 3210/c Itacoatiara-AM. +55(92) 99263-1315 e +55(92)99146-1890; E-mail de contato:

santosjoel229@gmail.com,Valdomiro@gmail.com.

https://doi.org/10.51189/rema/1950

Editora IME@ 2021. Todos os direitos reservados. 


\section{INTRODUÇÃO}

Atualmente metade das fontes de energias utilizadas são de origens não renováveis, como petróleo e gás natural que acarretam problemas ambientais com a liberação de dióxido de carbono, compostos sulfurados e nitrogenados. Para tal problema, boa proposta de energia limpa são os biocombustíveis, como o biodiesel de origem vegetal por ser renovável e biodegradável com baixa emissão de poluentes [1].

Dentre as famílias de plantas ocorrentes na Amazônia, as palmeiras Arecaceae assume importante papel, para uso na região, se destacando com os seus frutos [2], a bacaba Oenocarpus bacaba Mart., pertence a esta família, ocorrendo principalmente em matas secundárias, alcançando até $22 \mathrm{~m}$ de altura e $25 \mathrm{~cm}$ de diâmetro no caule e seu fruto tem coloração negro-violeta onde a polpa retirada e muito usada, porém a semente é descartada por não haver uso para a mesma [3].

Os óleos vegetais retirados de sementes são produtos naturais produzidos por uma mistura de ésteres derivados do glicerol (triacilgliceróis ou triglicerídeos) cujos ácidos graxos presentes contém de 8 átomos de carbonos com diferentes insaturação, conforme espécie, essa composição varia [4]. O uso de óleos vegetais para produção de combustível é conhecido principalmente pela reação e transesterificação para formação de mono-alquil de ácidos graxos e cadeias longas conhecidas como biodiesel $[5,6]$.

A rota produção de conversão do óleo para o biodiesel pela transesterificação é usada industrialmente por ser barata, e simples, em razão da reversibilidade usa-se um catalisador alcalino e um álcool, no Brasil geralmente toma-se a rota metílica com hidróxido de potássio, porém para conversões entre 94 e $96 \%$ outras existem outras condições no processo como temperatura controlada, agitação intensa e excesso de álcool $[7,8]$.

Em relação aos álcoois os mais utilizados são o metanol (rota metílica) e o etanol (rota etílica), sendo o metanol geralmente preferido, principalmente por razões econômicas e relacionadas ao processo de produção [9]. O metanol é mais barato que o etanol, é isento de água, possui cadeia mais curta e maior polaridade. Esta última propriedade torna mais fácil a separação entre $\mathrm{o}$ biodiesel e a glicerina. Contudo, a utilização de etanol pode ser atrativa do ponto de vista ambiental, uma vez que este álcool pode ser produzido a partir de uma fonte renovável que, ao contrário do metanol, não desperta tantas preocupações relacionadas com a toxicidade $[10,7]$.

Uma das vantagens do biodiesel também em questões ambientais destaca-se a ausência de enxofre e de compostos aromáticos que proporciona uma queima mais limpa sem formação de $\mathrm{SO} 2$ e de compostos cancerígenos, fora estes benefícios ambientais ainda pode ser uma alternativa econômica sobre a renda de milhares de famílias de trabalhadores rurais que estão ligados diretamente com o agronegócio ou realizam agricultura familiar [11].

Este biocombustível produzido pelo homem da floresta pode ser utilizado nas embarcações de pequeno porte, também pode ser utilizado nas turbinas de geração elétrica que é muito comum nos municípios do interior do Amazonas. Pois, no caso de ser empregado nos barcos, em ocorrência de vazamentos ou acidentes no rio, o biocombustível não causaria um impacto ambiental tão significativo se comparado ao gerado com o óleo diesel [12].

Neste contexto, dada as características favoráveis e a fácil obtenção de bacaba no Estado do Amazonas, sobretudo com predominância no município de Itacoatiara, é proposto neste trabalho o objetivo não apenas de produzir um biodiesel de qualidade, como também estudar as variáveis que afetam na reação, tendo em conta a viabilidade de economia para região e fonte para matriz energética brasileira.

\section{MATERIAL E MÉTODOS}

O material foi coletado de pequena empresa que trabalha com poupa para venda dentro da cidade de Itacoatiara, estes produtos 
são adquiridos de agricultores dos arredores $\mathrm{e}$ da Rodovia am-010 que liga a cidade a capital Manaus. Assim foram deixados coletores e uma vez por semana eram levados para o laboratório. Depois era separado os resíduos de casca da semente e levados ao sol por 3 dias, posteriormente secos na estufa por 6 horas a $60^{\circ} \mathrm{C}$.

Figura 1. Secagem das sementes na estuda por 6 horas a $60{ }^{\circ} \mathrm{C}$

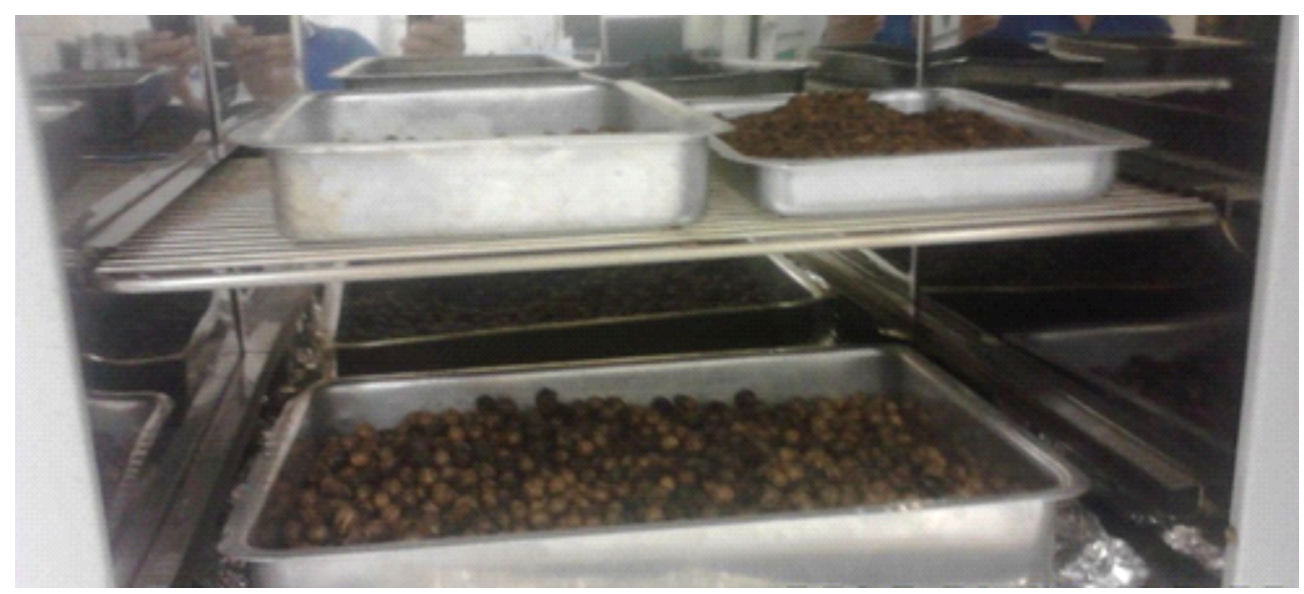

Fonte. autor 2019

\section{EXTRAÇÃO DO ÓLEO BRUTO}

Inicialmente as sementes foram submetidas a prensagem em uma prensa hidráulica a 27 toneladas, depois foram fatiadas em um moinho de facas para extração via solvente. A extração foi feita em um sistema soxhlet usando o solvente éter de petróleo.

Figura 2. A) Prensa B) sistema soxhlet usado na extração

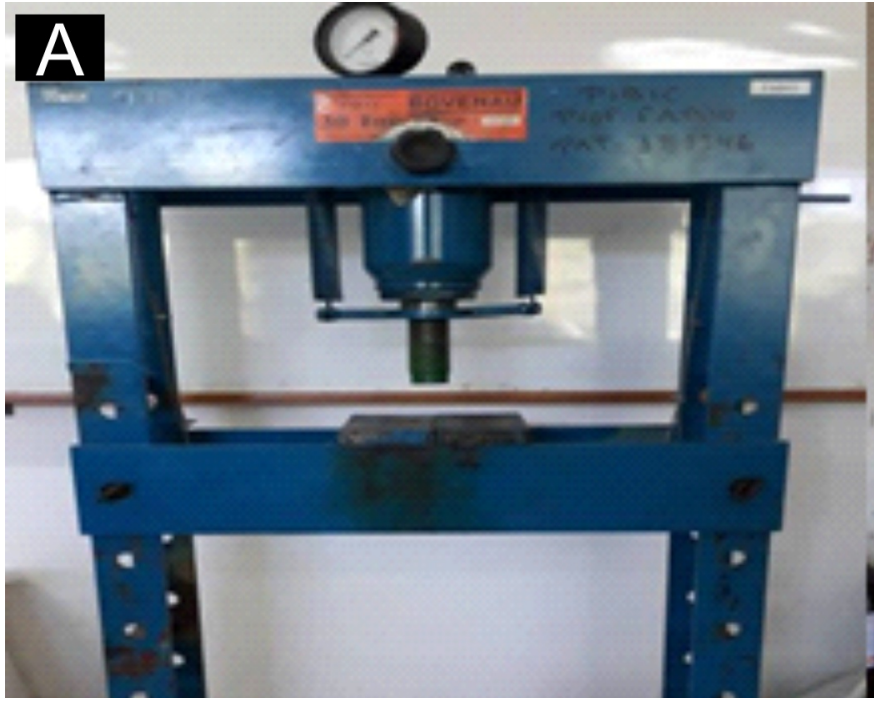

\section{ÍNDICE DE ACIDEZ}

Foi pesado $2 \mathrm{~g}$ da amostra em um Erlenmeyer de $125 \mathrm{ml}$ depois se adicionou 25 $\mathrm{ml}$ de solução de éter-álcool (1:1) neutra e duas gotas do indicador fenolftaleína, titulando com a solução de $\mathrm{KOH} 0,1 \mathrm{~mol} \mathrm{~L}^{-1}$ até o aparecimento da coloração rósea, que deverá persistir por 30 segundos, caso apresentar baixo teor de ácidos graxos, por exemplo, óleos e gorduras refinados, a mesma deverá

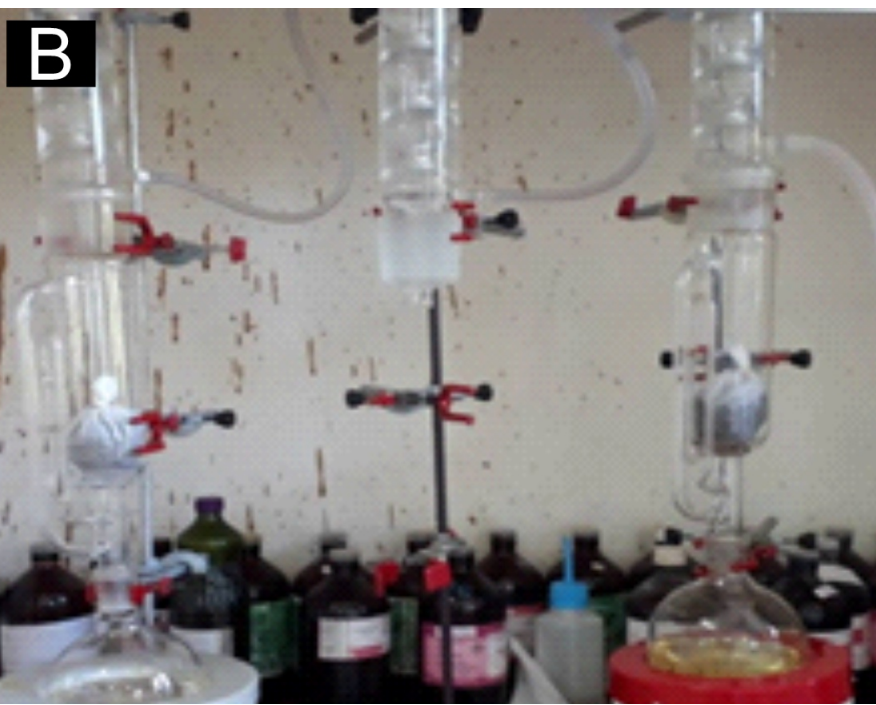

Fonte. Autor 2019

ser titulada com uma solução de $\mathrm{KOH}$ 0,001 mol L-1.

\section{ÍNDICE DE SAPONIFICAÇÃO}

Pesou-se uma quantidade de amostra, de tal modo que sua titulação corresponda de 45 a $55 \%$ da titulação do branco, por exemplo, $4 \mathrm{~g}$ adicionaram $50 \mathrm{ml}$ da solução alcoólica de $\mathrm{KOH}$. Então colocou-se o frasco contendo a amostra em chapa aquecedora e ferveu 
suavemente até a completa saponificação (aproximadamente uma hora, para amostras normais), depois do resfriamento, adicionou 1 $\mathrm{ml}$ do indicador e titulou com a solução de ácido clorídrico $0,5 \quad \mathrm{~mol}^{-1}$ até $\mathrm{O}$ desaparecimento da cor rósea.

\section{BIODIESEL}

Na fabricação do biodiesel foi utilizado um planejamento fatorial $2^{4}$, onde 2 representa os níveis (inferior e superior) das variáveis de controle na produção do biodiesel (quantidade de álcool, quantidade de catalisador, tempo de reação e temperatura) e 4 representa o número de variáveis. O planejamento fatorial $2^{4}(4$ variáveis com 2 níveis para cada uma delas) permitirá a realização de 16 ensaios, como indicado na Tabela 1.

Os níveis das variáveis a serem estudas serão: catalisador (hidróxido de sódio) $0,3 \mathrm{~g}(-)$ e $0,45 \mathrm{~g}(+)$; álcool (metanol) $30 \%$ (-) e $40 \%(+)$; tempo de reação $60 \mathrm{~min}(-)$ e $120 \mathrm{~min}(+)$; temperatura $25^{\circ} \mathrm{C}$ (ambiente) (-) e $50^{\circ} \mathrm{C}(+)$. Para cada um dos 16 ensaios será empregado $50 \mathrm{~g}$ de óleo.

Tabela 1. Planejamento fatorial $2^{4}$ a ser utilizado para realizar as reações de transesterificação.

\begin{tabular}{|c|c|c|c|c|}
\hline \multirow{2}{*}{ ENSAIOS } & \multicolumn{4}{|c|}{ FATORES } \\
\hline & Catalisador & Álcool & Tempo & Temperatura \\
\hline 1 & - & - & - & $\begin{array}{l}- \\
-\end{array}$ \\
\hline 2 & + & - & - & - \\
\hline 3 & - & + & - & - \\
\hline 4 & + & + & - & - \\
\hline 5 & - & - & + & - \\
\hline 6 & + & - & + & - \\
\hline 7 & - & + & + & - \\
\hline 8 & + & + & + & - \\
\hline 9 & - & - & - & + \\
\hline 10 & + & - & - & + \\
\hline 11 & - & + & - & + \\
\hline 12 & + & + & - & + \\
\hline 13 & - & - & + & + \\
\hline 14 & + & - & + & + \\
\hline 15 & - & + & + & + \\
\hline 16 & + & + & + & + \\
\hline
\end{tabular}




\section{RESULTADOS E DISCUSSÃO}

Para a quantidade pesada de $1000 \mathrm{~g}$ de sementes moídas foi retirado no final da extração $15.5064 \mathrm{~g}$ de óleo de bacaba cujo rendimento foi calculado usando a equação mencionada nos métodos, o valor foi de $15.51 \%$, comparando com a literatura [13], podemos encontrar para o óleo de soja um rendimento de $18 \%$, algodão $15 \%$, porém alguns tem valores bastantes elevados como a mamona 45-50\% , amendoim 40-43\% , colza $40-48 \%$ e girassol $38-48 \%$. O material retirado da semente de bacaba ficou dentro do rendimento das oleaginosas com maior procura no mercado, porém este valor pode aumentar, visto que, óleo fica impregnando no moinho de facas e com o calor do equipamento pode oxidar e se perder no processo.

O índice de acidez revela o estado de conservação de óleos e gorduras e pode ser definido como o número de miligramas de hidróxido de potássio necessário para neutralizar os ácidos graxos livres em $1,0 \mathrm{~g}$ de amostra. A hidrólise parcial dos glicerídeos é acelerada por aquecimento e pela luz, e a rancidez é quase sempre acompanhada pela formação de ácido graxo livre [14], para o óleo de bacaba o índice de acidez 1,92 mg de $\mathrm{KOH} /$ $\mathrm{g}$ de amostra, está dentro do padrões estabelecidos pelos órgãos e monitoramento que é de $3 \%$ para o óleo bruto também foi feito o índice de saponificação que é definido como o número de $(\mathrm{mg})$ de hidróxido de potássio $(\mathrm{KOH})$, necessários para saponificar os ácidos graxos, resultantes da hidrólise de um grama da amostra; é inversamente proporcional ao peso molecular médio dos ácidos graxos dos triglicerídeos presentes é importante para demonstrar a presença de óleos e gorduras de alta proporção de ácidos graxos, de baixo peso molecular, em misturas com outros óleos e gorduras.

Quanto menor o peso molecular do ácido graxo, tanto maior será o índice de saponificação, grosseiramente; para as gorduras vegetais, quanto mais altos os índices de saponificação mais se prestam para fins alimentares [14], Segundo o padrão britânico um óleo de primeira qualidade deve apresentar um índice de saponificação entre 177 a 187 mg $\mathrm{KOH} / \mathrm{g}$ de amostra, no óleo de mamona possui uma média de $180 \mathrm{mg} \mathrm{KOH} / \mathrm{g}$ um vez que muitos óleos possuem esses índices bem semelhantes entre 188 e 196, tal determinação é útil para a verificação do peso molecular médio de óleos e gordura e da adulteração por outros óleos com índice de saponificação bem diferentes. Para o óleo de bacaba o índice de saponificação foi de $179 \mathrm{mg}$ de $\mathrm{KOH} / \mathrm{g}$ de amostra estando dentro de valores encontrados na literatura.

Usando a tabela-1, obteve-se a tabela 2 como resultado considerando $30 \%$ e $40 \%$ de álcool-catalizador como deu-se inicialmente, e para cada amostra: foi utilizando $30 \mathrm{ml}$ de óleo bruto da bacaba e acrescentaram-se mais duas colunas: o rendimento final do biodiesel e a acidez do biodiesel. Os fatores que afetam uma reação química são amplamente estudas em cinética química, tais fatores podem favorecer ou desfavorecer a formação dos produtos, desses na indústria o tempo e proporção de reagentes são de muita importância. No trabalho, esses fatores foram estudas para prever o rendimento do biodiesel. Assim foram estudados valores de 40 e $30 \%$ de catalizador e álcool em relação a quantidade de óleo variando o tempo de agitação de 60 e 120 minuto, variando a de temperatura 25 e $50{ }^{\circ} \mathrm{C}$.

Para o rendimento depois de lavado e removido os resíduos de água e álcool, foi medido o volume de biodiesel, os ensaios em temperatura ambiente tiveram melhor rendimento que aquele que foram feitos em 50 graus, e houve pouca diferença em o percentual de 40 e $30 \%$, o ensaio 6 teve 86,66 $\%$ de transesterificação e os ensaios 2 e $3 \mathrm{com}$ 83,33 e $83,40 \%$, já os valores de rendimento para ensaios em $50{ }^{\circ} \mathrm{C}$ tiveram os menores rendimentos na amostra 16 e 10 respectivamente com 55,50 e $61,66 \%$ de biodiesel formado durante o tempo de reação.

Enquanto para os que foram feitos em temperatura ambiente ficaram entre $78,30 \% \mathrm{e}$ $86,66 \%$ rendimento assim o fator temperatura afetou no rendimento ainda que a agitação tenha sido a mesma, porém os ensaios feitos em temperatura de $50{ }^{\circ} \mathrm{C}$ ficaram apenas 12 
horas em decantação e ainda foi observado que após 30 minutos a glicerina e o biodiesel já estavam decantados, mesmo que o rendimento para um dos testes tenha ficado abaixo e $60 \%$ a maioria ficou entre 70 e $83 \%$ de rendimento. Este rendimento menor se deve a pouca instabilidade as ligações e os estéreis quebram suas cadeias ficando menores e aumentando a energia de ativação, portanto desfavorecendo a formação do biodiesel.

Outra observação foi proporção álcool e catalizador, em que a variação de rendimento para maioria dos testes está em $80 \%$ de rendimento, valores também reportados na literatura quanto a transesterificação de óleos vegetais, porém para 1 a 4 onde foram feitos para 60 minutos de agitação tais valores ficaram estáveis entre 81 e $83 \%$ de rendimento, logo um parâmetro crucial para obter melhores rendimentos é o tempo em que as espécies ficam em contanto na agitação.
Umas das características para um biodiesel consumível no mercado é o índice de acidez, isto porque um alto índice prejudica o motor, e isto é um indicador da instabilidade do biodiesel, mostrando que existe uma rápida oxidação do mono-alquil, para o método utilização no trabalho e segundo as especificações brasileiras 0 valor tem 0 máximo de $0,50 \mathrm{mg} \mathrm{KOH} / \mathrm{g}$ de amostra, recorrendo a tabela 2 onde encontram os respectivos valores obtidos para o biodiesel produzido usando o planejamento fatorial $2^{4}$.

O biodiesel produzido a partir do óleo extraído da semente de babaca mostrou-se pouco estável, uma vez que nenhum dos valores de acidez ficou dentro do limite estipulado peça ABNT, porém, os ensaios 7, 12 e 13 firam próximos, estudos sobre a instabilidade do biodiesel de bacaba podem dar melhores valores, e explicações para assegurar melhor estabilidade do material.

Tabela 2. Resultados numéricos para o planejamento com os respectivos valores de rendimento e índice de acide do biodiesel.

\begin{tabular}{|c|c|c|c|c|c|c|}
\hline \multirow{2}{*}{ ENSAIOS } & \multicolumn{5}{|c|}{ FATORES } & \multicolumn{2}{c|}{$\begin{array}{c}\text { Tempo } \\
(\mathrm{mim})\end{array}$} & $\begin{array}{c}\text { Temperatura } \\
\left({ }^{\circ} \mathrm{c}\right)\end{array}$ & $\begin{array}{c}\text { Rendimento } \\
(\%)\end{array}$ & $\begin{array}{c}\text { Índice de } \\
\text { acide }(\mathrm{mg} \\
\text { KOH/g) }\end{array}$ \\
\hline 1 & 0,3 & 9 & 60 & 25 & 81,16 & 0,71 \\
\hline 2 & 0,45 & 9 & 60 & 25 & 83,33 & 0,68 \\
\hline 3 & 0,3 & 12 & 60 & 25 & 83.4 & 0,65 \\
\hline 4 & 0,45 & 12 & 60 & 25 & 78,3 & 0,60 \\
\hline 5 & 0,3 & 9 & 120 & 25 & 80 & 0,63 \\
\hline 6 & 0,45 & 9 & 120 & 25 & 86,66 & 0,63 \\
\hline 7 & 0,3 & 12 & 120 & 25 & 78,33 & 0,52 \\
\hline 8 & 0,45 & 9 & 60 & 25 & 80 & 0,60 \\
\hline 11 & 0,3 & 12 & 60 & 50 & 70 & 0,65 \\
\hline 12 & 0,45 & 9 & 60 & 50 & 83,33 & 0,54 \\
\hline 9 & 0,45 & 9 & 60 & 50 & 80 & 0,57 \\
\hline
\end{tabular}




\begin{tabular}{|c|c|c|c|c|c|c|}
\hline ENSAIOS & $\begin{array}{c}\text { Catalisador } \\
(\mathrm{g})\end{array}$ & $\begin{array}{c}\text { Álcool } \\
(\mathrm{ml})\end{array}$ & $\begin{array}{c}\text { Tempo } \\
(\mathrm{mim})\end{array}$ & $\begin{array}{c}\text { Temperatura } \\
\left({ }^{\circ} \mathrm{c}\right)\end{array}$ & $\begin{array}{c}\text { Rendimento } \\
(\%)\end{array}$ & $\begin{array}{c}\text { Índice de } \\
\text { acide }(\mathrm{mg} \\
\mathrm{KOH} / \mathrm{g})\end{array}$ \\
\hline 13 & 0,3 & 12 & 60 & 50 & 73,33 & 0,54 \\
\hline 14 & 0,45 & 9 & 60 & 50 & 78,3 & 0,65 \\
\hline 15 & 0,3 & 12 & 60 & 50 & 66,7 & 0,71 \\
\hline 16 & 0,45 & 9 & 60 & 50 & 55,5 & 0,68 \\
\hline
\end{tabular}

Fonte. Autor 2019

\section{CONCLUSÃO}

O óleo retirado da semente de bacaba tem um rendimento de $15 \%$ por $\mathrm{kg}$ de semente, valores semelhantes são encontrados na literatura o mesmo se reporta do índice de acidez do óleo e saponificação que está dentro dos valores estipulados por outros trabalhos. O óleo de bacaba tem maior rendimento de transesterificação em temperatura ambiente, do que em temperatura elevada, e quanto maior a agitação maior a probabilidade de acelerar a reação, uma vez que no trabalho foi constado que os melhores valores foram em temperatura ambiente e com maior agitação ainda que o tempo de contado tenha sido o mesmo.

Os valores de rendimentos para temperatura ambiente se mostraram promissores, a maioria está acima de $80 \%$, todavia, estes valores podem ser melhorados com estudos mais detalhados quanto a agitação e percentual de álcool-catalizador, mesmo que os valores em temperatura elevada tenham sido inferior, os tempo de decantação diminuíram de 24 para 12 horas, podem ainda ser menor, uma vez foram constados depois e 30 minutos as duas fases estavam completamente evidentes. Quanto a acidez do biodiesel, os resultados mostraram pouca estabilidade com o tempo, ainda que podendo ser produzido, mas para uso torna-se inviável sem um estudo mais detalhado.

\section{CONFLITO DE INTERESSE}

Não há conflito de interesse na pesquisa.

\section{REFERÊNCIAS}

[1] ROCHA, D. Q, BARROS, D., COSTA, E.C., de SOUSA, K.S.,POSSOS, R.R., VEIGA JUNIOR, V. F., CHAAR, J. S., determinação da matéria-prima utilizada na produção do biodiesel adicionado ao diesel mineral através de monitoramento seletivo de íons. Quim. Nova, Vol. 31, No. 5, 1062-1066, 2008.

[2] NAZARIO, P.,FERREIRA. A., Emergência de plântulas de patauá (Oenocarpus bataua Mart.) em função do dessecamento das sementes. Informativo ABRATES. vol.22, $n^{\circ} .1,2011$.

[3] GIMARÂES, A. G., Potencial funcional de farinha de jerivá (sagrusromanzoffiana) e bacaba (Oenorcarpus bacaba). Dissertação (mestrado)-Universidade Federal de Lavras, f. 114, 2013.

[4] COSTA NETO, P. R., ROSSI, L. F., Produção de biocombustível alternativo ao óleo diesel através da transesterificação de óleo de soja usado em frituras. Quim. Nova, 23(4) (2000).

[5] CHESTI, G. F., MACEDO, J. L., DIAS, J. A., DIAS, S. I., Produção de biodiesel via transesterificação etílica com zeólitas básicas. Quim. Nova, Vol. 35, No. 1, 119-123, 2012.

[6] IVANI, S. de A., Caracteres quantitativos de interesse para a determinação da variação genética em população de Oenocarpus bacaba MART.,(Aracaceae) no 
Amapá. Dissertação (mestrado)- Universidade Estadual Paulista, Faculdade de Ciências Agraria e Veterinárias. p. 51, jabuticabal, 2010.

[7] OLIVEIRA, D.S., FONSECA, X. D., FARIAS, P. N., BEZERA, V. S., PINTO, C. H., SOUSA, L. D., MATIAS, L. G., Obtenção do biodiesel através da transesterificação do óleo de Moringa Oleífera Lam. HOLOS, Ano 28, Vol 1, 2012.

[8] ARAZANI, F. A, GOMES, M. C. S, PEREIRA, N. C., Biodiesel: production by ethylc transesterification of the canola oil and separation of the glicerol by ultrafiltration. Revista de saúde, meio ambiente e sustentabilidade, vol.8, n. 1, p. 122-126, 2013.

[9] RAMOS, L. P., CESAR, M.A., MUNIZ, A. S., NAKAGAKI, S., KRIEGER, N., WYPYCH, F., CORDEIRO, C. S., Biodiesel: Matérias-Primas, Tecnologias de Produção e Propriedades Combustíveis. Rev. Virtual Quim. |Vol 9| |No. 1| |317-369. 2016.

[10] NATIONAL BIODIESEL BOARD; In: Anais do Congresso Internacional de Biocombustíveis Líquidos. Instituto de Tecnologia do Paraná; Secretaria de Estado da Ciência, Tecnologia e Ensino Superior; Curitiba, PR, Brasil: 19 a 22 de julho, p. 42, 1998.

[11] ARZANI, F. A.; GOMES, M. C. S.; PEREIRA, N. C.; Biodiesel: produção por transesterificão etílica do óleo de canola e separação do glicerol por ultrafiltração. Revista de Saúde, Meio Ambiente e Sustentabilidade, Vol. 8, n. 1, p. 111-16, 2013.

[12] CHRISTOFF, P. Produção de biodiesel a partir do óleo residual de fritura comercial. Dissertação de Mestrado (Desenvolvimento de Tecnologia, Instituto de Tecnologia para Desenvolvimento - LACTEC), 2006.

[13] ARAUJO, F. D. da S., MOURA, C. V. R., CHAVES, M. H., Biodiesel metílico de Dipteryx lacunifera: preparação, caracterização e efeito de antioxidantes na estabilidade a oxidação. Química Nova, vol. 33, No. 8, p. 171-
1676, 2010.

[14] MORETTO, E.; FETT, R. Tecnologia de Óleos e Gorduras Vegetais, na indústria de alimentos. Livraria Varela: São Paulo, 1998. 